\title{
Nacimiento de la juridización en Argentina. Historizando el proceso de creación de legislaciones indigenistas*
}

\author{
Birth of juridicity in Argentina. Historizing the process of creation of \\ indigenist legislations
}

\begin{abstract}
Miguel Leone ${ }^{* *}$
Resumen: El artículo comprende los procesos de juridización de la diferencia indígena como el efecto de dinámicas localmente arraigadas. Postula que hacia finales de la década de 1960 se configuró en la región chaqueña argentina un espacio político-pastoral de naturaleza interétnica, con fuerte presencia de agentes eclesiásticos adherentes a la teología de la liberación. A continuación, construye un vínculo conceptual e interpretativo (históricamente fundamentado) entre este particular espacio social y la sanción de distintas legislaciones indigenistas. Son analizados en detalle los casos de la Ley Integral del Aborigen (Formosa, 1984), la Ley del Aborigen Chaqueño (Chaco, 1987) y la sanción del artículo constitucional № 75 (1994) para captar las dinámicas de circulación -de personas, ideas y prácticas- a través de las cuales esos hitos jurídicos alcanzaron a producirse.
\end{abstract}

Palabras clave: Argentina, iglesia católica, pueblos originarios, política indigenista, derecho indígena

\begin{abstract}
The article studies the juridization processes of the native difference as the effect of locally rooted dynamics. It suggests that, at the end of 1960's decade, it has configured in the Argentinian Chaco region a political, pastoral and interethnic social space which strong presence of ecclesiastical agents. After that, it is built a conceptual and interpretative bond (historically based) between that particular social space and the sanction of distinct indigenous legislations. The article analyzes in detail the cases of the Ley Integral del Aborigen (Formosa, 1984), Ley del Aborigen Chaqueño (Chaco, 1987) and the sanction of the number 75 constitutional article (1994) to reconstruct the dynamics of circulation -of people, ideas and practices- through which these juridical events had crystallised in law.
\end{abstract}

Key words: Argentine, Catholic Church, indigenous peoples, indigenous policy, indigenous rigths

Recibido: 17 febrero 2018

Aceptado: 18 marzo 2018

\footnotetext{
* La elaboración de este artículo y la investigación que el mismo refleja fueron hechas con el apoyo financiero del Consejo Nacional de Investigaciones Científicas y Técnicas (CONICET) en el marco de una Beca Interna Doctoral (2012-2017).

*** Argentino. Sociólogo y Doctor en Ciencias Sociales. Instituto de Estudios de América Latina y el Caribe, Universidad de Buenos Aires / Consejo Nacional de Investigaciones Científicas y Técnicas (CONICETArgentina). Correo electrónico: miguelleone@ hotmail.com
} 


\section{Introducción}

La configuración de esquemas jurídicos de reconocimiento de derechos de los pueblos originarios es una de las novedades más relevantes que lo indígena ha mostrado durante los últimos tiempos. En América Latina, el fenómeno comenzó a observarse, fundamentalmente, a partir de los años ochenta del siglo XX. Varios autores lo han definido como un proceso de juridicidad o juridización del derecho indígena a la diferencia cultural ${ }^{1}$. Con ello, ciertas dimensiones de los modos de vida de los pueblos originarios consiguieron penetrar el sistema legal de los Estados, aunque también, en el mismo juego, acabaron siendo penetradas por éstos. ${ }^{2}$

En tanto marca selectivamente a ciertos sujetos y grupos, dicha juridización produce aboriginalidad creando nuevos lugares de inscripción en la grilla hegemónica de funcionamiento del orden social. Aun así, puesto que postula reconocimientos diferenciales de adscripción étnica, la juridización también habilita nuevos espacios de subjetivación y reivindicación política. ${ }^{3}$

La juridización conlleva una dimensión geopolítica de alcance mundial; relacionada con el multiculturalismo, en tanto "lógica cultural del capitalismo multinacional", la globalización neoliberal, los pliegues producidos hacia dentro de campo de los derechos humanos, y el desenvolvimiento de nuevos procesos de identificación. En el caso argentino, se caracterizó por un período de aparición de legislaciones indigenistas puntuales que, durante la década de 1980, buscaron regular de forma integral las relaciones entre indígenas y no-indígenas. Luego alcanzó su punto más alto (que, en definitiva, no lo fue tanto) en 1994, a partir de la sanción del artículo $N^{\circ} 75$ inciso 17 en la nueva Constitución Nacional argentina. ${ }^{5}$

\footnotetext{
${ }^{1}$ Gómez, Magdalena, "Derecho indígena y constitucionalidad”, en: Krotz, Esteban (ed.), Antropología jurídica: perspectivas socioculturales en el estudio del derecho, Barcelona, Anthropos, 2002, p. 245, y Briones, Claudia, "Formaciones de alteridad: contextos globales, procesos nacionales y provinciales", en: Briones, Claudia (ed.), Cartografías argentinas. Políticas indigenistas y formaciones provinciales de alteridad, Buenos Aires: Antropofagia, 2005, p. 9.

${ }^{2}$ El Convenio 107 de la OIT (1957) representó un primer hito en la historia de la juridización de derechos indígenas y su internacionalización. A ello le siguió un tiempo de relativo silencio en la materia que comenzó a ser revisado a lo largo de los años setenta y ochenta.

${ }^{3}$ Rancière, Jacques, El desacuerdo. Política y filosofía, Buenos Aires, Ediciones Nueva Visión, 1996.

${ }^{4}$ Žižek, Slavoj. "Multiculturalismo o la lógica cultural del capitalismo multinacional", en: Fredric Jameson y Slavoj Žižek, Estudios Culturales. Reflexiones sobre el Multiculturalismo, Buenos Aires, 2001, Paidós, 137188.

${ }^{5}$ El mismo reconoció "la preexistencia étnica y cultural de los pueblos indígenas argentinos", "la personería jurídica de sus comunidades" y la "posesión y propiedad comunitaria de las tierras que tradicionalmente ocupan"; garantizó "el respeto a su identidad y el derecho a una educación bilingüe e intercultural" y aseguró la participación de los pueblos en "la gestión referida a sus recursos naturales y a los demás intereses que los afecten” (Constitución Nacional Argentina [1994], art. 75, inc. 17).
} 
Ahora bien, si las transformaciones de orden global e internacional intervienen de manera mediada (diferencial) en los distintos casos nacionales y locales, la juridización merece ser pensada a partir de complejos procesos convergentes en los que las alianzas y las coyunturas puntuales reacomodan el espacio de lo posible. Consecuentemente, la comprensión sobre cómo se concretiza el proceso de juridización en cada caso exige un análisis pormenorizado sobre los escenarios políticos y económicos nacionales y una historización de las tramas de solidaridad y las redes políticas efectivamente operantes: agentes locales de lobby, alianzas, organización, planeación estratégica, movilización de recursos, entre otras cosas.

Este artículo propone un ejercicio de historización de las redes de activación política que impulsaron el proceso de juridización en el caso argentino. A modo de hipótesis se asume que dichas redes comenzaron a gestarse hacia finales de la década de 1960 y emergieron en el seno de un particular espacio político-pastoral de naturaleza interétnica, en el que resultó protagónica la acción de hombres y mujeres provenientes de las iglesias cristianas, fundamentalmente la católica, e inscriptos - de forma variable y laxa - en la teología de la liberación.

\section{Desarrollo}

\section{Surgimiento y territorialización de un espacio político-pastoral interétnico}

La construcción de derechos es un proceso complejo cuya explicación y naturaleza se funda en motivos sociológicos e históricos antes que jurídicos. Atendiendo a ello, toda pregunta sobre el origen y funcionamiento de la jurisprudencia ha de ser necesariamente interdisciplinaria e histórica y convenientemente empírica ${ }^{6}$; pues debe poner en relación el campo de lo jurídico con otros campos de la vida social muchas veces alejados de aquel. En esta clave de interpretación, proponemos construir un vínculo conceptual e interpretativo entre la concreción de formas de juridización de lo indígena durante las décadas de 1980 y 1990 en Argentina y la configuración, durante los años finales de la década de 1960, de un particular espacio de creación de relaciones de etnicidad en la región chaqueña de este país.

En dicha década, el Concilio Vaticano II (1962-1965) convocaba a traducir el Evangelio al idioma del pueblo, la Revolución Cubana inspiraba a laicos, sacerdotes y monjas a "comprometerse" con "la transformación social", y las revisiones dentro de las Iglesias protestantes hacía lo propio entre pastores y obispos. En ese marco, hacia finales de esa década, comenzó a desplegarse en la región del Chaco argentino una variedad de acciones

\footnotetext{
${ }^{6}$ Barros Geraldo, Pedro; Fontainha, Fernando y Veronese, Alexandre, "Sociologia empírica do direito: Uma introdução", Revista Ética e Filosofia Política, No 12, vol. 2, Julho de 2010, 1-13
} 
inscriptas en el tercermundismo católico ${ }^{7}$ destinadas a la "promoción del aborigen" que, en el propio proceso, lo "acompañara" en su "liberación".

Un caso ampliamente conocido en ese escenario ha sido el que -en 1969- emprendió la hermana Guillermina Hagen junto a un grupo de voluntarios, en la que otrora fuera la misión Nueva Pompeya ${ }^{8}$. Aunque menos conocidas, otras experiencias también fueron importantes. Cuatro años antes, la Iglesia metodista había inaugurado una misión en la localidad de Juan José Castelli, unos 165 kilómetros al sureste de Nueva Pompeya9 . Por esos años, a su vez, la orden de la Pasión de Jesucristo ("pasionistas") viró sus estrategias misionales, impulsando el compromiso de varios de sus seminaristas para que se asentaran de forma permanente en la región chaqueña y conformaran comunidades eclesiales de base $^{10}$. En pocos años, sacerdotes y seminaristas pasionistas sea afincaron en Ingeniero Juárez y El Potrillo (en Formosa), El Sauzalito (en Chaco), entre otros puntos de misión. También se sumó la iniciativa de otras congregaciones (v.g. Sagrado Corazón de Jesús; Hermanas de la Doctrina Cristiana; Compañía de María) asentadas en esas y otras localidades de la región como Laguna Yema, Campo Bandera, Pozo del Tigre (en Formosa), El Colchón (en Chaco) o Morillo (en Salta). Los obispos de Sáenz Peña (Monseñor Di Stéfano) y de Formosa (Monseñor Scozzina) apoyaron este tipo de iniciativas al tiempo que la Fundación para el Desarrollo en Justicia y Paz (FUDAPAZ) y el Instituto de Cultura Popular (INCUPO) funcionaron como nodos articuladores de esa multiplicidad.

En definitiva, en un lapso relativamente breve se produjo en la región un proceso de territorialización de un específico espacio político-pastoral de contacto interétnico. Desde nuestra perspectiva, en el seno de este espacio se articularon originales prácticas de etnicización $^{11}$, procesos de creación de sentidos (político, ideológico, identitario y teológico) y visiones sobre "la diferencia indígena" (no pocas veces fueron reproducidas nociones objetivantes e incluso biologizantes en torno de "la raza" y la "autoctonía").

\footnotetext{
${ }^{7}$ Touris, Claudia, "Entre Marianne y María. Los trayectos de las religiosas tercermundistas en la Argentina", en: Andújar, Andrea, D'Antonio, Débora, Gil Lozano, Fernanda, Grammático Karin y Rosa, María Laura (comps.), De minifaldas, militancias y revoluciones: Exploraciones sobre los `70, Buenos Aires: Luxemburg, 2009, 51-68.

${ }^{8}$ Iñigo Carrera, Nicolás, "La participación política de los indígenas chaqueños: algunos antecedentes, Misión Nueva Pompeya, 1952-1970", en: Teurel, Ana y Omar Jeréz (eds.), Pasado y presente de un mundo postergado: estudios de antropología, historia y arqueología del Chaco Pedemonte Surandino, San Salvador de Jujuy: Universidad Nacional de Jujuy, 1998, 221-242.

9 Almirón, Victoria, "Alfabetización y textos de lectura en qom: Elena qataq Elí y Lede Na Qom (19641976)", XXII Reunión de Comunicaciones Científicas y Tecnológicas de la Universidad Nacional del Nordeste. Corrientes, 14 y 15 de junio de 2016.

10 Taurozzi, Susana, Los pasionistas en Argentina y Uruguay: 100 años de historia, Buenos Aires, Pasionistas, 2006, 241.

11 Briones, Claudia, "Mestizaje y blanqueamiento como coordenadas de aboriginalidad y nación en Argentina", RUNA, XXIII, 2002, 61-88.
} 
Las relaciones sostenidas con gente wichi, pilagá y qom condujeron a los agentes de pastoral de Formosa y Chaco a revisar sus criterios de comprensión y producción de la diferencia étnica. Harder Horst planteó que, en el Chaco paraguayo, los pueblos originarios forzaron a misioneros y misioneras a realizar nuevos aprendizajes y modificar muchas de sus prácticas ${ }^{12}$. Lo mismo pudo observarse en el caso que nos ocupa. Aquí tuvieron lugar situaciones concretas de interacción social en las que el sujeto ubicado en la posición de "objeto" de intervención consiguió reconfigurar y transformar al sujeto interventor ${ }^{13}$. En efecto, es evidente -aunque no está de más recordarlo- que la continuidad en el tiempo de estas relaciones no dependió sólo de la voluntad de los misioneros, sino también del interés, la aceptación la participación y el compromiso que la gente wichi, qom y pilagá tuvo en ellas. Así se observa, por ejemplo, que, paulatinamente, los misioneros fueron especificando la abstracta idea de "liberar" "al aborigen" en una más clara y estratégica de "acompañarlo en las luchas fundamentales por la tierra"14. De igual modo, reformularon sus propuestas desarrollistas de "promover", educar y alfabetizar en español, y en cambio comenzaron a estudiar los idiomas indígenas recreando formas bilingües de alfabetización.

Atendiendo a aquellos virajes en sus propuestas misionales, los agentes de pastoral se interesaron en producir dinámicas de agregación de demandas políticas entre la gente del lugar. Ello contribuyó a que el espacio político-pastoral funcionara como un ámbito de creación de símbolos, significaciones y modalidades particulares de "ideología étnica"15. Deliberadamente los agentes de pastoral buscaron producir formas de comunalización y sentidos de pertenencia ${ }^{16}$ ligadas a las categorías identitarias de "comunidad" y/o "pueblo aborigen". Desde su punto de vista, había que establecer "un diálogo" con "lo indígena" buscando "hacer tomar consciencia a la gente; consciencia de que son personas, que son razas, lo más lindo que tenemos en América (...) que ellos descubran la vuelta a su cultura, y (...) que sobrepasen su pequeño pueblo y [puedan] ver todos sus hermanos". ${ }^{17}$

Por cierto, este espacio político-pastoral es un caso puntual de un fenómeno emergente en la mayor parte de los países de América Latina. Como señaló Iturralde Guerrero, la iglesia católica, a través de la creación de Comunidades Eclesiales de Base, ha tenido una notable influencia en el proceso de reconstitución de las comunidades indígenas y los agentes de

\footnotetext{
${ }^{12}$ Harder Horst, Rene, "Breaking Down Religius Barriers. Indigenous People and Christian Churches in Paraguay", in: Edward L. Cleary and Timothy J. Steigenga, Resurgent Voices in Latina America: Indigenous Peoples, Political Mobiization and Religious Change, New Brunswick, New Jersey, London, Rutgers University Press, 2004, 65-92.

${ }^{13}$ Pacheco de Oliveira, João, Ensaios em Antropologia Histórica, Rio de Janeiro, UFRJ Editora, 1999 , p. 30.

${ }^{14}$ Breve Reseña del proyecto de Promoción de la comunidad toba-pilagá. Parroquia de Ibarreta, s/f [c. 1985], CECAZO, cajas, ${ }^{\circ}$ 203, Formosa, Argentina. p. 2.

${ }^{15}$ García-Ruíz, Jesús, "De la identidad aceptada a la identidad elegida: el papel de lo religioso en la politización de las identificaciones étnicas en Guatemala”, Estudios Sociológicos X, n 30, $1992,716$.

${ }^{16}$ Brow, James, "Notes on community, hegemony, and the uses of the past", Anthropological Quarterly, n' 63, vol. 1, 1990, 1-6.

${ }^{17}$ Primer Encuentro de Pastoral Indigenista del Cono Sur de América Latina, 15 de febrero de 1980, p. 21.
} 
pastoral (catequistas indígenas, diáconos) ejercieron un papel importante en el tejido de redes político-organizativas. ${ }^{18}$

Promediando la década de 1970, la creciente represión dio lugar a ciertas reformulaciones de este espacio. Con seguridad, la experiencia de Nueva Pompeya fue el caso más traumático. En noviembre de 1973 la experiencia llegó a su fin y Hagen tuvo que exiliarse en Perú. Sin embargo, no pasó lo mismo con los otros casos que, por el contrario, continuaron funcionando a lo largo de toda la década del setenta; incluso bajo la cruenta dictadura inaugurada en 1976. En 1979 las misiones indigenistas católicas consiguieron dar forma a un Centro de Capacitación Zonal (CECAZO) en la localidad de Pozo del Tigre, el cual funcionaría, desde entonces, y hasta la actualidad, como un lugar de encuentros entre gente wichi, qom y pilagá ${ }^{19}$. Asistían a estas reuniones (denominadas como Encuentros de Hermanos) representantes indígenas oriundos de El Potrillo, Campo Bandera, Ingeniero Juárez, Laguna Yema, Las Lomitas, El Porteñito, San Martín II, Qompí (Pozo del Tigre), Cacique Coquero, San Nicolás e Ibarreta, entre otros lugares. Como describe Laura Zapata,

en general las sesiones comenzaban con una charla/conferencia dictada por un sacerdote en la que retomaba los temas tratados en la reunión anterior mientras el grueso del público escuchaba. Posteriormente los participantes eran organizados en pequeños grupos, de acuerdo a su comunidad de pertenencia y distinguidos de los agentes eclesiales, y se les proponían algunas consignas que guiaban las discusiones grupales. A las reflexiones grupales le seguían plenarios en los que un representante por grupo exponía los temas debatidos a la asamblea plenaria. ${ }^{20}$

Los encuentros realizados en el CECAZO contribuyeron a la articulación de un novedoso espacio de organización indígena regional. Los contenidos de estas actividades eran plasmados en "cartillas" cuidadosamente preparadas con criterios pedagógicos. Ellas funcionaban como textos "prácticos"; preparadas para que fueran estudiadas en forma grupal y utilizadas como herramientas orientativas para la acción organizativa. Según señalaba la publicación semanal de INCUPO (Acción de Incupo), de los Encuentros de Hermanos y otros encuentros semejantes, "los aborígenes salían con ánimos de empezar o continuar el camino de la organización: escuelas de apoyo para niños aborígenes,

\footnotetext{
${ }^{18}$ Iturralde Guerrero, Diego, "Demandas indígenas y reforma legal: retos y paradojas", Alteridades, vol. 7, n" 14, 1997, 81-98.

${ }^{19}$ Leone, Miguel, "Prácticas de pastoral aborigen y juridización de derechos indígenas en Argentina. Un análisis de la región del Chaco (1965-1994)", Tesis doctoral inédita, Universidad Nacional de General Sarmiento-Instituto de Desarrollo Económico y Social, Los Polvorines, Buenos Aires, 1 de noviembre de 2016.

${ }^{20}$ Zapata, Laura, "Pastoral aborigen y categorías de identificación de poblaciones indígenas en Formosa (1960-1984)", Uturunco Achachi. Revista de pueblos y culturas originarios, (2), diciembre 2013, 58.
} 
cooperativas de trabajo, carpinterías, hornos, y el reclamo siempre presente por las tierras". ${ }^{21}$

El CECAZO mantuvo una serie de vínculos políticos, académicos y eclesiásticos (a nivel nacional e internacional), que fortalecieron su operatividad. Como miembro del Consejo de Administración de FUNDAPAZ, José Luis de Ímaz fue uno de los importantes intelectuales que visitaron el $\mathrm{CECAZO}^{22}$. También lo hicieron teólogos de Brasil como Paulo Suess y José Marins, al tiempo que existió un nutrido intercambio de bibliografías y publicaciones con otros espacios de pastoral aborigen de América Latina. ${ }^{23}$

Dar cuenta de la existencia de este espacio político-pastoral habilita una mejor comprensión sobre el proceso de construcción y sanción de la primera de las legislaciones indigenistas de la recuperación del régimen democrático en Argentina: la ley formoseña promulgada en 1984 bajo el nombre de Ley Integral del Aborigen. Para demostrarlo, será necesario adentrarse en el análisis de esa coyuntura histórica.

\section{Juridización en Formosa}

Con el fin de la dictadura (1983) se abrieron nuevos canales de participación y expresión social. Lo indígena comenzó a ser tematizado en los medios de comunicación, muchas veces insertándose en el campo discursivo de los derechos humanos. Entonces, la geografía provincial de inclusión/exclusión de tipo étnico ${ }^{24}$ mostró en Formosa una particular inflexión. Ello se produjo en el marco de importantes cambios en el uso capitalista de los suelos. Las tierras de Chaco y -sobre todo- Formosa comenzaron a ser requeridas por productores ganaderos pampeanos para la producción cárnica destinada al consumo interno. Al mismo tiempo, se trató de un escenario en el que, a nivel global, la cultura pasó a ser un bien susceptible de ser patentado, mercantilizado y consumido ${ }^{25}$. En ese contexto, políticos, funcionarios y militantes de los partidos radical y peronista de Formosa comenzaron a "ver a los indígenas como un electorado apetecible y a vislumbrar el potencial político de la etnicidad y la cuestión de la tierra". ${ }^{26}$

\footnotetext{
${ }^{21}$ Acción de Incupo, septiembre de 1990, p. 17.

22 A partir de los aprendizajes hechos en su condición de experto comprometido con este tipo de organizaciones cristianas, el sociólogo publicó, en 1979, Una estrategia de promoción humana (Buenos Aires, Editorial Sudamericana).

${ }^{23}$ Porantim, año V, No 51, mayo de 1983, p. 13; Iluminación del equipo de Marins, c. 1984, p. 7, Archivo CECAZO, f66, Formosa, Argentina.

${ }^{24}$ Briones, op. cit.

${ }^{25}$ Comaroff, Jean y Comaroff, John L., "Naturalizando la nación: aliens, apocalipsis y el estado postcolonial”, Revista de Antropología Social, (11), 2002, 89-133.

${ }^{26}$ Spadafora, Ana María; Gómez, Mariana y Matarrese, Marina, "Rumbos y laberintos de la política étnica: organizaciones unificadas y faccionalismos indígenas en la provincia de Formosa (pilagá y toba)", en: Gordillo, Gastón y Silvia Hirsch, (comps.), Movilizaciones indígenas e identidades en disputa en la Argentina, Buenos Aires: La Crujía, 2010, 245.
} 
Durante la campaña electoral, en 1983, el candidato a gobernador por el Partido Justicialista, Floro Bogado, se esforzó en construir una alianza con el espacio políticopastoral configurado en la provincia. Junto a su esposa y candidata a diputada provincial, Adriana Bortolozzi, Bogado visitó varias de las localidades en las que misioneros y misioneras indigenistas se encontraban asentados ${ }^{27}$. Más tarde, tras el inicio de la gestión justicialista (10 de diciembre de 1983), algunos agentes de pastoral fueron incorporados al organigrama estatal: el sacerdote pasionista, Francisco Nazar Anchorena (radicado durante más de una década en El Potrillo) y el laico Ernesto Stechina (uno de los fundadores del CECAZO), pasaron a trabajar para el Instituto Provincial del Aborigen.

A los ojos de políticos y gobernantes, la voz del indigenista blanco, cristiano y de clase media o alta se apareció como un referente central y legítimo para hablar sobre los derechos de los pueblos indígenas; por momentos, incluso más legítimo que los propios "aborígenes", reactualizando un histórico patrón de aboriginalidad que, al tiempo que anula la voz indígena, reconoce en el cristianismo un gestor válido de las cuestiones indígenas. La de Nazar fue una voz particularmente tenida en cuenta en los debates sobre la futura ley ${ }^{28}$. Aun así, en abril de 1984, el gobierno provincial decidió crear una comisión en la que siete representantes indígenas de cada una de las tres etnias reconocidas por la provincia (wichí, qom y pilagá) ${ }^{29}$ oficiaran de contralores y asesores del Poder Ejecutivo en la elaboración de un proyecto de "ley aborigen". En virtud de su número total de miembros, se la denominó "Comisión de los 21 ".

Acompañando las actividades de esta Comisión, los agentes de pastoral aborigen formoseños promovieron la realización de encuentros de referentes políticos indígenas destinados a debatir las reivindicaciones que debían ser incorporadas en la ley. El primero de ellos tuvo lugar en mayo, en el centro Hermana Teresa de la Parroquia San Francisco en la Ciudad de Formosa. El segundo se realizó en la localidad de Ingeniero Juárez (uno de los principales núcleos de funcionamiento del espacio político-pastoral interétnico) entre el 14 y el 15 de julio, bajo el lema "Tierra y pensamiento aborigen".

Evidentemente, la juridización del derecho indígena a la diferencia cultural es un proceso contradictorio: por un lado, es el efecto de lo posible dentro de específicos reordenamientos en el plano de la gubernamentalidad y las lógicas de acumulación del capital. Pero, por otro lado -y al mismo tiempo-, es el resultado de las luchas sostenidas por grupos autoidentificados como indígenas y otros sectores aliados a ellos. Se trata de dinámicas en las que los esquemas de subalternización etnizante por momentos consiguen ser críticamente reapropiados y reutilizados en estrategias de reafirmación étnica autónoma. En esta clave, Nazar explicitaba su lectura sobre los horizontes de acción en esa particular coyuntura política:

\footnotetext{
${ }^{27}$ Entrevista a Ernesto Stechina realizada por el autor, 4 de julio de 2013, Formosa.

${ }^{28}$ La Mañana, 9 de abril de 1984, p. 9.

${ }^{29}$ La etnia nivacle quedó sin representación. Actualmente, ocho comunidades de este pueblo se encuentran jurídicamente reconocidas.
} 
Estamos experimentando los primeros pasos de una vida en libertad, después de ocho años de la más atroz dictadura que hemos vivido (...) Nuestro gobierno [actual] no es revolucionario ni tiene en su pensamiento el cambio de estructuras, pese a que en el exterior pueda tener una buena imagen. No obstante ello, estamos aprovechando los espacios de libertad para radicalizar nuestra lucha en la causa indígena. Tierras, autodeterminación, respeto de la cultura, organizaciones indígenas, derogación de leyes etnocidas y toma de consciencia de la sociedad envolvente son nuestras prioridades. Difícil y lento, como todo lo que crece de abajo hacia arriba. Pero fuerte y pujante como toda raíz. ${ }^{30}$

El 11 de julio de 1984, el gobernador Bogado entregó a la Legislatura provincial el proyecto de Ley Integral del Aborigen. Entonces los grupos vinculados al CECAZO organizaron un tercer encuentro -el cual se llevó a cabo en el Barrio Toba-Nam Qom de la ciudad de Formosa durante los días 25, 26 y 27 de julio- para que dicho proyecto de ley fuera analizado minuciosamente por unos noventa referentes indígenas de la provincia. Convocados por los agentes de pastoral aborigen, los abogados Armando Cabrera y Juan Díaz Roig se ocuparon de explicar minuciosamente los artículos del proyecto de ley y tomaron nota de las propuestas de modificación hechas por los líderes indígenas ${ }^{31}$. La declaración final del encuentro exigió títulos de propiedad de las tierras y devolución de aquellas usurpadas $^{32}$. Al cierre del evento asistieron el Gobernador de la Provincia y los Ministros de Acción Social (Patricio E. Kelly) y de Salud Pública (Eduardo Macedo).

Inmediatamente después, el 31 del mismo mes, fue organizada una movilización que nucleó más de dos mil personas -la mayor parte perteneciente a los pueblos wichi, pilagá y qombajo el lema: "Pueblos aborígenes unidos y de pie". Al cierre del evento, el presidente de la "Comisión de los 21" Manuel Chascoso habló en nombre de los pueblos indígenas de la provincia y entregó las modificaciones que proponían incorporar al proyecto de ley siguiendo las ideas debatidas en el encuentro de referentes indígenas realizado pocos días antes. A su izquierda, el gobernador formoseño escuchaba atento el discurso. A su derecha, lo hacía Francisco Nazar. Este último fue invitado a continuación a presenciar el debate legislativo en un lugar de honor. ${ }^{33}$

Esa misma noche del primero de agosto de 1984 -en un "un clima de optimismo y euforia" por estar en una "jornada histórica" 34 - la "Ley Integral del Aborigen" (No 426/84) fue sancionada por la Legislatura incorporando las enmiendas apeladas por la Comisión de los $21^{35}$. En la ley se plasmó parte de los objetivos sostenidos desde antaño en el espacio

\footnotetext{
${ }^{30}$ Porantim, año VII, No 68, octubre de 1984, p. 2.

${ }^{31}$ Porantim, op. cit., p. 10.

${ }^{32}$ Nuevo Diario, 26 de mayo de 1984, p. 5.

${ }^{33}$ HCD, Provincia de Formosa, exp. 335, 2 de agosto de 1984, p. 1.

${ }^{34}$ Idem.

${ }^{35}$ Porantim, op. cit., p. 10.
} 
político-pastoral-interétnico: la demanda de títulos de tierra ${ }^{36}$, "educación del aborigen para preservar su salud", "formación de agentes sanitarios aborígenes", "puesta en funcionamiento de Salas de Primeros Auxilios (...) en las distintas comunidades", "enseñanza bilingüe", alfabetización, "aplicación del sistema de auxiliares docentes aborígenes", difusión de "la cultura, cosmovisión e historia aborigen" y "creación de fuentes de trabajo" (art. 21, Ley 436/84).

Llegados a este punto, la ilación entre la conformación de aquel espacio político-pastoral e interétnico y el proceso de juridización producido en la provincia resulta clara. Fortalece estas evidencias la propia voz indígena: en 2005, a instancias de un Taller de Formación y Diagnóstico Jurídico realizado en Ingeniero Juárez, el referente wichi Ignacio Guillalba (miembro de la Comunidad Barrio Obrero de Ingeniero Juárez y de la Comisión de los 21) rememoró los hechos señalando:

La idea venía desde 1976 para lograr los derechos indígenas en el territorio formoseño. Empezamos a capacitarnos los hombres grandes para desarrollar e interpretar este proyecto. Se necesitaron muchos elementos humanos, libros y leyes. Logramos que nos acompañen abogados porque necesitábamos personas que nos asesoren en esto. Nos hemos reunido acá en Ingeniero Juárez. Después de este encuentro hemos tenido otro en el Cecazo en Pozo del Tigre. Vimos el desafío de la ley y vimos que las leyes nos deben salir a favor. (...) Hemos conversado todo esto con los abogados. Entonces comenzó la democracia y hemos ido a Formosa y gracias a hermanos de la Iglesia Católica que nos dieron un lugar pudimos juntarnos y debatir. ${ }^{37}$

\section{Juridización en Chaco}

La experiencia de Formosa fue continuada con una dinámica semejante en la vecina provincia de Chaco. También allí la reconstrucción de la democracia dio lugar al ingreso de lo indígena en los debates políticos. En febrero de 1984, el flamante gobernador Florencio Tenev se reunió con referentes indígenas de la provincia ${ }^{38}$. Semanas después firmó el decreto $\mathrm{N}^{\circ}$ 899/84 que creó el Consejo Provincial del Aborigen: una instancia consultiva dependiente de forma directa del Poder Ejecutivo provincial e integrado por representantes de los tres grupos étnicos entonces oficialmente reconocidos ("matacos", "tobas" y "mocovíes").

\footnotetext{
${ }^{36}$ Vale aclarar, sin embargo, que esta ley -como así también las otras "leyes aborígenes" de los años ochentano reconoció territorios a los pueblos. Se limitó, por el contrario, a otorgar títulos de propiedad comunitaria a núcleos de familias indígenas sobre tierras áridas, con suelos altamente deteriorados y de escaso valor para la inversión del capital.

${ }^{37}$ Memoria de la creación de la Ley Integral del Aborigen, Taller de Formación y Diagnóstico Jurídico para hombres Wichí, Ingeniero Juárez. 19 al 21 de septiembre del 2005. Servicio Jurídico de Pueblos Indígenas del Centro Oeste de Formosa. Archivo privado de Francisco Nazar, p. 3.

${ }^{38}$ La Mañana, 24 de febrero de 1984, p. 4.
} 
El Poder Ejecutivo se interesó por registrar, contabilizar y administrar los grupos de "población aborigen" asentados en el territorio. Es por ello que, entre 1984 y 1985, la Dirección del Aborigen del Chaco trabajó mancomunadamente con la Dirección de Estadísticas de esa provincia para realizar un censo indígena que permitiera conocer fehacientemente su número y distribución" ${ }^{39}$. Hacia 1986, la idea de sancionar una "ley aborigen" comenzó a hacerse cada vez más generalizada. En ese contexto, el espacio político-pastoral e interétnico que había tenido un papel protagónico en la sanción de la ley formoseña, pasó a funcionar como gestor de esa nueva intención juridizadora gubernamental.

Para entonces, dicho espacio había mostrado un significativo crecimiento organizacional. Por un lado, es preciso observar que la injerencia alcanzada sobre el espacio gubernamental formoseño -materializada de forma contundente en los casos de Ernesto Stechina y Francisco Nazar- fue aún más fuerte en el caso de la provincia de Chaco. En efecto, quien fuera director de la Junta Unida de Misiones (JUM), Carlos Benedetto, pasó a ocupar el cargo de Director del Instituto Provincial del Aborigen en esa provincia. ${ }^{40}$

Por otro lado, conviene tener presente que, desde finales de 1984 en adelante, los miembros católicos de este espacio político-pastoral pudieron contar con una entidad orgánica hacia dentro de la Iglesia específicamente abocada al trabajo pastoral con indígenas. Ellos fueron quienes impulsaron la creación de una Comisión de Pastoral Aborigen (CEPA) en la Conferencia Episcopal Argentina (CEA) y un Equipo Nacional de Pastoral Aborigen (ENDEPA) que funcionaría como organismo ejecutivo de dicha Comisión. ${ }^{41}{\text { La } \mathrm{IL}^{\circ}}^{\circ}$ Asamblea Plenaria episcopal aceptó sin dilaciones la propuesta de crear estas instancias y, a continuación, los agentes de pastoral de Formosa y Chaco pasaron a ocupar los principales espacios del nuevo Equipo Nacional. En un principio, la activista laica Mabel Quinteros (con experiencia de trabajo pastoral en Morillo e Ingeniero Juárez) tomó a su cargo el Secretariado Ejecutivo de la entidad. Al año siguiente, éste pasó a manos de Francisco Nazar y su sede se ubicó en la ciudad de Formosa.

La creación de ENDEPA reubicó las relaciones entre los agentes indigenistas chaqueños y los Estados en un espacio distinto de interlocución. Ya no fueron sólo misioneros altruistas

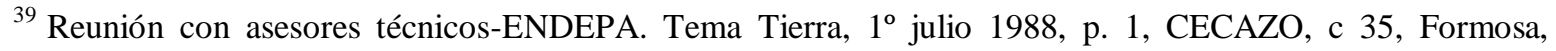
Argentina.

${ }^{40}$ La incorporación de agentes de pastoral a la política estatal indigenista conformó un patrón a lo largo del tiempo. Dan cuenta de ello los casos de Roberto Vizcaíno, Patricio Doyle y Jorge Pereda Bullrich. El primero fue seminarista pasionista -afincado como agente de pastoral en Nueva Pompeya (1971), Ingeniero Juárez (1971) y El Potrillo (1972) - que en el año 2000 pasó a ser director del Instituto de Comunidades Indígenas (ICA) de la provincia de Formosa. Doyle fue sacerdote pasionista, agente de pastoral en El Sauzalito, y en 1995 integró el Instituto Nacional de Asuntos Indígenas (INAI), cuando el organismo estaba bajo la dirección de Jorge Pereda. Éste había sido fundador de FUNDAPAZ (en 1973) y su director durante más de diez años.

${ }^{41}$ ENDEPA se estructuró a través de un Equipo Episcopal, integrado por tres obispos nombrados por la CEA (Jaime de Nevares, Dante Sandrelli y Gerardo Sueldo, bajo la presidencia de este último); un Secretariado Ejecutivo; además de varias Asambleas Nacionales y regionales.
} 
los que hablaron en nombre de "los aborígenes", sino la iglesia católica como institución. A partir de allí, el espacio político-pastoral nacido hacia finales de la década del sesenta en la región chaqueña pasó a contar con una sólida herramienta orgánica e institucional con la que coordinar trabajos indigenistas a nivel nacional, interpelar a hombres y mujeres de Estado, e intervenir en dinámicas juridizadoras provinciales y nacionales. En la sanción de la "ley aborigen" chaqueña esto se volvió evidente.

Entre el 28 de julio y el 1 de agosto de 1986 unos ciento ochenta referentes indígenas del Chaco se reunieron en la ciudad de Sáenz Peña dando lugar a la Primera Asamblea de Comunidades Indígenas de la provincia. INCUPO, JUM y ENDEPA fueron las principales organizaciones no indígenas que apoyaron la realización de la Asamblea ${ }^{42}$. La Dirección del Aborigen del Chaco, al mando de Benedetto, también acompañó la iniciativa y aportó financiamiento.

El tema central de la Asamblea fue el problema de "la inseguridad jurídica en la adjudicación y usufructo de las tierras". Puntualmente, se discutieron los riesgos concretos de desalojo a las "comunidades" 43 . Luego del encuentro, los dirigentes indígenas hicieron llegar a manos del Gobernador una nota en la que reclamaron un millón de hectáreas (poco más del $10 \%$ de la superficie provincial) en concepto de derechos territoriales.

Como sucediera en Formosa, la Asamblea desembocó en la creación de una comisión destinada a negociar con dependencias gubernamentales para impulsar una "ley aborigen". Al igual que lo hiciera la "Comisión de los 21", la comisión chaqueña apuntó a generar una representación equitativa de los distintos pueblos originarios de la provincia. Ella contó con dos representantes por el pueblo mocoví, dos por el pueblo qom, y dos por el pueblo wichí; adoptando la denominación de "Comisión de los seis". El pueblo vilela careció de toda representación.

Los agentes de pastoral acompañaron a la Comisión en las diversas gestiones que esta realizó ante instancias gubernamentales. El 6 de noviembre de 1986, la Comisión se reunió en la localidad de Quitilipi con el Ministro de Gobierno, Justicia y Educación de la provincia para solicitar la presentación de un proyecto de "ley aborigen" a la Legislatura provincial. El mismo recuperó los puntos emergentes en la reunión, y varios artículos de la ley Integral del Aborigen de la vecina provincia. Semanas después, el Poder Ejecutivo presentó el proyecto ante la Legislatura provincial ( $\left.\mathrm{N}^{\circ} 471 / 86\right)$.

Como se hiciera en Formosa, también en Chaco el espacio político-pastoral interétnico propulsó movilizaciones conducentes a la aprobación del proyecto en la Legislatura. Según

\footnotetext{
42 ENDEPA, Documentos de ENDEPA, Memoria 2005, Formosa: Equipo Nacional de Pastoral Aborigen, 2006 , p. 5.

${ }^{43}$ Guarino, Graciela, "Estrategias identitarias para la resistencia étnica en las organizaciones indígenas Qom del Chaco", Revista Mad, n²2, mayo de 2010, 63-64.
} 
señaló Acción de Incupo, "el ejemplo cercano de la provincia de Formosa"44 había sido un fuerte elemento impulsor de las movilizaciones indígenas en Chaco. Acompañando el inicio de las sesiones legislativas de 1987, el 1 de marzo tuvo lugar una primera movilización. Ella fue replicada dos meses después y continuada con un acampe frente a la legislatura provincial, el cual se prologó por tres días.

La presión política de las movilizaciones surtió efecto y la comisión parlamentaria de Legislación General se comprometió a que el proyecto de ley fuese tratado "sobre tablas" en la sesión ordinaria del 13 de mayo de 1987. Los puntos más debatidos fueron los referidos al destino y la adjudicación de las tierras. No obstante, al día siguiente, el proyecto de ley fue aprobado sin modificaciones sustanciales ${ }^{45}$ como Ley "de las comunidades indígenas" ( $\mathrm{N}^{\mathrm{o}} 3258$, más conocida como Ley del Aborigen Chaqueño). Con ello, Chaco se convirtió en la tercera provincia en aprobar una ley aborigen durante la década del ochenta ${ }^{46}$. En el trayecto recorrido, el espacio político-pastoral espacio acumuló una experiencia inédita que habría de ser aprovechada para intervenir en otros procesos de juridización, incluso de alcance nacional y de naturaleza constitucional.

\section{Abrir el espacio}

Las discusiones públicas respecto de la necesidad de una reforma constitucional comenzaron a aparecer hacia 1988. En línea con ello, hacia 1990, ENDEPA adoptó el objetivo de "apoyar la Reforma Constitucional" 47 y "garantizar los derechos indígenas" en dicha reforma. La entidad creó, junto a varios líderes indígenas y otras ONGs indigenistas, un Foro Permanente por los Derechos de los Pueblos Indígenas que se orientó a promover en la esfera pública un amplio debate sobre las relaciones entre Pueblos Indígenas y Estado. El Foro contó con el respaldo y el financiamiento de la Subsecretaría de Derechos Humanos de la Nación. Su objetivo principal fue impulsar la derogación del artículo 67 inciso 15 de la Constitución de 1853, el cual asignaba al Congreso de la Nación el deber de "proveer la seguridad de las fronteras, conservar el trato pacífico con los indios y promover la conversión de ellos al catolicismo". Por su parte, el periódico Acción de Incupo se convirtió en un activo difusor del evento, subrayando la importancia de que la próxima reforma constitucional tuviera "en cuenta, declare y garantice los derechos de los aborígenes argentinos". 48

\footnotetext{
${ }^{44}$ Acción de Incupo, op. cit., p. 20.

${ }^{45}$ Diario de Sesiones HCD, Provincia de Chaco, 13 de mayo, 1987; ENDEPA, informe 20 años de la Ley del Aborigen Chaqueño y Diario Norte, 14 de mayo,1987.

${ }^{46}$ El año anterior lo había hecho la provincia de Salta (Ley No 6373/86 “de promoción y desarrollo del aborigen").

47 4to asamblea-encuentro Nacional. ENDEPA. Material de apoyo, 1990, p. 6, CECAZO, f37, Formosa, Argentina.

48 Acción de Incupo, marzo de 1990, p. 5.
} 
La primera de las actividades del Foro Permanente fue la realización de las jornadas de debate tituladas: "Los indígenas en la Reforma de la Constitución Nacional". Llevadas a cabo en la ciudad de Buenos Aires a finales de marzo de 1990, contaron con la asistencia de referentes indígenas oriundos de Patagonia, la región noroeste (NOA) y noreste (NEA). Éstos debatieron con legisladores y abogados no indígenas al tiempo que miembros de ENDEPA como Francisco Nazar, Ricardo Altabe y Germán Bournisen ocuparon roles referenciales en la organización de la actividad.

En las palabras de apertura del evento, el titular de la Dirección Nacional de Derechos Humanos, Guillermo Frugoni Rey, señaló que la participación de "los aborígenes" en la gestión de sus derechos en el ámbito constitucional debía hacerse buscando "alianzas con aquellas instituciones y personas no indígenas que les permitan garantizar los derechos del indígena en la Constitución Nacional" ${ }^{49}$. Como Secretario Ejecutivo de ENDEPA, y, asumiéndose destinatario de las palabras de Frugoni Rey, Nazar afirmó: "lo importante de este encuentro es el habernos encontrado aborígenes del interior del país y los que están en Buenos Aires, y las instituciones que trabajamos con los aborígenes". 50

Como en los otros casos reseñados, los asistentes de las Jornadas emitieron una Declaración final. Esta vez, exigiendo que "los representantes de los Pueblos Indígenas participen en la redacción, discusión y votación en el proceso constituyente que se instaure por la Reforma Constitucional", 51

A continuación, entre el 5 y el 10 de junio de 1990 se llevó a cabo en el CECAZO un Encuentro sobre Derechos del Aborigen con el explícito objetivo de replicar, a nivel de la región del NEA, lo que se había alcanzado a discutir en las Jornadas realizadas en Buenos Aires. Alrededor de treinta referentes indígenas de las provincias de Formosa, Chaco, Misiones, Salta, Santa Fe y Santiago del Estero se trasladaron a la localidad de Pozo del Tigre.

Nuevamente, el periódico Acción de Incupo divulgó las noticias del evento. Con una tirada reducida pero una distribución selectiva, este periódico alcanzaba a llegar a distintos poblados rurales del norte y sur del país, y era una eficaz herramienta de divulgación. En sus páginas, el referente chané (oriundo se la provincia de Salta), Jorge Segundo describió el encuentro en los siguientes términos:

Hemos venido de varias provincias y somos distintas etnias. De la provincia de Salta vinimos chané, chiriguano, kolla y wichí. Aquí están también los tobas y los wichí de Chaco. Llegaron hermanos mbyá guaraní

\footnotetext{
${ }^{49}$ Idem.

${ }^{50}$ Idem.

${ }^{51}$ Carrasco, Morita, El movimiento indígena anterior a la reforma constitucional y su organización en el Programa de Participación de Pueblos Indígenas. Universidad de Buenos Aires, 2002. Recuperado de http://lanic.utexas.edu/project/etext/llilas/vrp/carrasco.pdf, 57.
} 
de la provincia de Misiones. Tuve la alegría de conocerlos. De la provincia de Formosa estuvieron los pilagá y wichí. Siempre quise encontrarme y a Dios gracias, pude conocer a mocovíes de Santa Fe que vinieron con los tobas de esa provincia ${ }^{52}$.

Por su parte, Ruperto Chará, qom de la provincia de Santa Fe, señaló:

En el encuentro nos dimos cuenta que aunque reclamamos nuestros derechos, poco podemos conseguir. En la Ley Central de la Argentina que es la Constitución Nacional, a los indígenas no se nos tiene en cuenta. Por eso, si ahora va a haber reforma constitucional como dicen por ahí, tenemos que hacer escuchar nuestra voz y llegar a los que van a cambiarla. Queremos que reconozcan que existimos y que tenemos derechos $^{53}$.

El cierre del Encuentro dejó establecida una serie de derechos que deberían ser reconocidos en las leyes y la Constitución Nacional:

Derecho a vivir. Derecho a ser diferente: a ser aborigen, a tener una raza propia, derecho a la tierra propia: a nuestro idioma, música costumbres. Derecho a vivir en comunidad: nuestros antiguos vivían así y pensamos que es bueno. Derecho a la educación: en los dos idiomas, en el del blanco y en el nuestro. Derecho a la salud: que usemos lo que la ciencia del blanco tiene de bueno y también nuestra medicina natural. Derecho a la autodeterminación: somos dueños de nuestro destino. El blanco no nos debe imponer qué camino tomar. ${ }^{54}$

De esta forma, la alianza estratégica entre agentes de pastoral y referentes indígenas gestada tiempo atrás en las provincias de Formosa y Chaco operó como soporte de vehiculización de nuevos procesos de organización política, esta vez, de alcances mucho más amplios. Por un lado, las experiencias acumuladas en torno de las luchas por las "leyes aborígenes" en esas provincias brindaron un sólido capital político al espacio político-pastoral, desde donde éste interpeló a otros pueblos, comunidades y referentes indígenas del país. Por otro lado, los procesos de institucionalización producidos por los agentes de pastoral al compás de esas luchas (expresados, por ejemplo, en la operatividad de ENDEPA, CECAZO o INCUPO) funcionaron como una plataforma sólida desde la cual hacer crecer una espiral organizativa de alcance nacional. Eso fue, en efecto, lo que operó a lo largo de los años 1992 y 1993, cuando ENDEPA promovió la realización de talleres y charlas en distintas

\footnotetext{
${ }^{52}$ Acción de Incupo, julio de 1990, p. 5.

${ }^{53}$ Ibid., p. 6.

${ }^{54}$ Idem.
} 
comunidades indígenas del país para discutir sobre derechos indígenas y reforma constitucional. $^{55}$

Por cierto, la centralidad que en esta lógica tenían sectores vinculados a la iglesia católica muchas veces generó tensiones de difícil resolución. Fue frecuente que líderes de organizaciones indígenas desconfiaran de la autenticidad con la que los agentes de pastoral se comprometían en las causas. La pertenencia eclesiástica de éstos siempre fue fuente de sospechas y suspicacias. Al mismo tiempo, fue habitual que aquellos agentes de pastoral con estrechos vínculos con comunidades indígenas rurales pusieran en duda la representatividad de dirigentes indígenas que, por vivir en las ciudades u orientar su lucha en el campo de los organismos internacionales, carecían de ese tipo de vínculos.

\section{Aprovechar el espacio}

Cuando la Cámara de Diputados de la Nación comenzó a discutir la ley de reforma constitucional, ENDEPA vigiló de cerca el proceso. A fin de que los derechos indígenas ingresaran entre los puntos a ser debatidos por la futura Convención, durante la semana del 12 de octubre de 1993 ENDEPA organizó un nuevo encuentro entre agentes de pastoral y referentes indígenas de todo el país. El documento final, titulado "Declaración de los representantes de los pueblos indígenas" (más conocido como Declaración de Octubre) dejó explícita la convergencia entre el indigenismo eclesiástico y el movimiento indígena al tiempo que disimuló las referidas tensiones:

somos representantes de los pueblos indígenas kolla, tapiete, wichí, pilagá, toba, mocoví, mapuche, chané y chiriguano que nos hemos convocado en la ciudad de Buenos Aires del 11 al 14 de octubre de 1993, junto al Equipo Nacional de Pastoral Aborigen, para reclamar como pueblos preexistentes que habitan Argentina desde siempre, que ante la eventual reforma de la Constitución Nacional se incorporen en la Ley que declara la Necesidad de la reforma constitucional el reconocimiento de nuestra existencia como pueblos indígenas y, en consecuencia, junto a los derechos que nos corresponden, el reconocimiento de Argentina como país pluriétnico y pluricultural. ${ }^{56}$

La Asesoría Jurídica de ENDEPA elaboró la fundamentación jurídica de la propuesta, bajo autoría de Ricardo Altabe y Jorge Abel González. Para delimitar las formas que debería tener la entrega de tierras a los pueblos originarios, apelaron al artículo $\mathrm{N}^{\circ} 9$ de la ley del Aborigen del Chaco.

\footnotetext{
${ }^{55}$ Mombello, Laura, Evolución de la política indigenista en Argentina en la década de los noventa, Neuquén: Proyecto Self-Sustaining Community Development in Comparative Perspective, 2002.

${ }^{56}$ Declaración de Octubre. Declaración de los representantes de los pueblos indígenas, Buenos Aires, 14 de octubre de 1993.
} 
ENDEPA hizo explícito al rol que quería ocupar en el proceso: "como Equipo Nacional de Pastoral Aborigen queremos presentar su situación, la realidad de estos 500 mil hermanos ["aborígenes"] y solicitar que se tenga en cuenta su existencia como grupo minoritario. Pero como grupos pre existentes a nuestra propia organización como país" 57 . Al mismo tiempo, buscaba legitimar esa posición en virtud de una "autoridad moral" basada en la presencia junto a los pueblos originarios "a lo ancho y largo del país, acompañando a las comunidades". 58

La ley que puso en marcha la reforma constitucional ( $\mathrm{N}^{\circ}$ 24.309) fue votada por el Congreso de la Nación el 29 de diciembre de 1993, justo antes de que el recinto entrara en período de receso. El encuentro y la Declaración de octubre resultaron ser vitales para que dicha ley contemplase la "adecuación de los textos constitucionales a fin de garantizar la identidad étnica y cultural de los Pueblos Indígenas" (Ley 24.309, art. 3, inc. LL). Ellos consiguieron quebrar la resistencia del oficialismo a que se incorporaran en el proceso de reforma cuestiones ajenas a los mezquinos intereses del Poder Ejecutivo nacional: la habilitación de la re-elección presidencial y las reformas estructurales exigidas por los organismos internacionales de crédito.

A partir de allí se abrió una nueva etapa conducente a intervenir en la definición del contenido concreto que los derechos indígenas constitucionales debían tener.

Los agentes de pastoral depositaron buena parte de su estrategia en el obispo de Neuquén, Jaime de Nevares; electo como convencional por la Unión Cívica Radical. Sin embargo, el mismo día de la inauguración de la Convención Constituyente ${ }^{59}$ éste renunció al cargo reclamando así por las excesivas limitaciones que el oficialismo había impuesto al debate constitucional. ${ }^{60}$ En consecuencia, los activistas eclesiásticos indigenistas buscaron hacer alianzas con otros convencionales. Uno de los vínculos que resultaron estratégicos fue el establecido con la diputada Elisa Carrió. Oriunda de la provincia del Chaco, ésta mantenía contacto con algunos de los miembros fundadores de la Asesoría Jurídica de ENDEPA (años atrás había sido docente de Jorge González y Ricardo Altabe en la Universidad del Nordeste). Otro vínculo valioso fue el establecido con el otrora gobernador formoseño, ahora convencional por esa provincia, Floro Bogado. Pero sin lugar a dudas, la alianza que mayor relevancia tuvo en el proceso fue la establecida con la presidenta de la Comisión de Nuevos Derechos y Garantías, la abogada Elba Roulet, pues fue esa la Comisión que tomó a su cargo el debate sobre los derechos de los pueblos originarios.

${ }_{58}^{57}$ ENDEPA, Informe: "Para ir ampliando la información...”, p. 1.

${ }^{58}$ Idem.

${ }^{59}$ La Convención Constituyente fue inaugurada el 25 de mayo de 1994 en la ciudad de Paraná, provincia de Entre Ríos. A continuación, las sesiones se realizaron en la ciudad de Santa Fe, en instalaciones de la Universidad del Litoral.

${ }^{60}$ Página/12, 11 de abril de 1994, p. 3 y Página/12, 26 de julio de 1994, p. 4. 
Varias organizaciones indígenas se hicieron presentes en la Convención. Tal los casos de la Organización de Comunidades Aborígenes de Santa Fe (OCASTAFE), la Coordinadora de Organizaciones Aborígenes de Jujuy (COAJ), la Asociación Indígena de la República Argentina (AIRA) (a través del abogado kolla Eulogio Frites y los referentes Rogelio Guanuco y Gabino Zambrano), la Coordinadora de Organizaciones Mapuches (a través de Luis Pilquiman, Jorge Nahuel y Roberto Nancucheo), y el Consejo de Aborígenes de Jujuy (a través Nimia Apaza; integrante, a su vez, de la Comisión Interamericana de Juristas Indígenas). En total, asistieron a la asamblea unos cien referentes y líderes políticos indígenas.

Varios asistentes solventaron sus viajes a través del apoyo brindado por la Secretaría de la Presidencia de la Nación ${ }^{61}$. Otros encontraron en ENDEPA los recursos necesarios. Además, el Equipo financió "la estadía permanente de un grupo más o menos numeroso de indígenas en Santa Fe para que realizaran las actividades de cabildeo entre los constituyentes y mantuvo a la Asesoría Jurídica a disposición de unos y otros" "62. A su vez, junto con INCUPO, JUM y otras "instituciones acompañantes" del movimiento indígena ${ }^{63}$ hizo gestiones para que fuera permitida la presencia de representantes indígenas (y referentes indigenistas) en el recinto de la Convención. Miembros de ENDEPA consiguieron disponer de una casa en la localidad de Sauce Viejo, en las afueras de la ciudad de Santa Fe, para que funcionara como albergue de los referentes indígenas. Mabel Quinteros, entonces secretaria en ENDEPA, permaneció en Santa Fe durante los dos meses que duró la Convención y fue anfitriona del grupo de cabildeo rotativo. Según cuenta esta activista laica,

cada lunes venían veinticinco [referentes indígenas] y se quedaban toda la semana. Porque estábamos con la JUM, con [la Asociación] Amigos del Aborigen, con Incupo. Entonces venían los abogados de Endepa, un abogado que trabajaba el mundo aborigen, Maldonado, que estaba acá en Buenos Aires, y estaban toda la semana y el viernes se empezaban a ir. Y el lunes llegaba otra remesa. Y venían con los compañeros de las distintas instituciones que también se iban turnando. ${ }^{64}$

Al respecto, un cuadernillo conmemorativo editado por ENDEPA e INCUPO señala:

A los poquitos días del inicio [de la Asamblea Constituyente], empezaban a llegar a Santa Fe indígenas de las distintas etnias del país, junto a representantes de instituciones que los apoyaban. Renovándose cada semana, su presencia sería como una velada, una guardia para asegurarse

\footnotetext{
${ }^{61}$ Página/12, Suplemento, 28 de agosto de 1994.

${ }^{62}$ Carrasco, op. cit. p. 10

${ }^{63}$ Los indígenas en la Reforma Constitucional. Con presencia y protagonismo, ENDEPA-INCUPO, octubre de 1994.

${ }^{64}$ Entrevista a Mabel Quinteros realizada por el autor, 13 de abril de 2015, Buenos Aires.
} 
de que la cuestión indígena se trataría y se sancionaría de acuerdo a lo pedido por las comunidades. ${ }^{65}$

Muchos de entre quienes llegaron a Santa Fe eran históricos participantes de las actividades generadas en torno del CECAZO. Tal los casos de Luis Paniagua, referente mocoví de la provincia de Santa Fe, que había asistido al Encuentro sobre Derechos del Aborigen realizado en el CECAZO en 1990 ${ }^{66}$ (ENDEPA, 2007: 14) y Alfredo García, primer maestro pilagá de la provincia de Formosa, oriundo de una comunidad cercana a Pozo del Tigre y vinculado a los espacios decisorios del CECAZO.

La constante circulación de activistas eclesiásticos y referentes indígenas en la Convención dio lugar a que el grupo fuera denominado como "los convencionales de pasillo" ${ }^{67}$ y su práctica de lobby catalogada como la "más eficaz de la Convención" 68 . Como refería el citado cuaderno conmemorativo de ENDEPA, el grupo se preocupaba por

ir a los bloques [partidarios], conversar con cada miembro de la Comisión de Redacción, convencer para que el texto aprobado por la Comisión de nuevos derechos y garantías sea aprobado sin modificaciones, apurar a los que querían poner piedras en el camino para que los derechos indígenas no sean aprobados o sean aprobados con lo mínimo. ${ }^{69}$

Otra forma de generar las presiones políticas fue la realización de distintas actividades de difusión y discusión paralelas a las sesiones plenarias de la Convención. Así se organizó, por ejemplo, el panel "Identidad étnica y cultural de los Pueblos Indígenas" que contó con un público numeroso ante el cual expusieron sus ideas el abogado y asesor de AIRA, Horacio Maldonado; el secretario ejecutivo del Fondo Indígena Latinoamericano ${ }^{70}$; y Francisco Nazar, en representación de ENDEPA. ${ }^{71}$

Fueron muchos los proyectos de modificación del artículo constitucional $\mathrm{N}^{\mathrm{o}} 67$ presentados ante la Comisión de Nuevos Derechos de la Convención. Organismos de derechos humanos como APDH y el Movimiento Ecuménico por los Derechos Humanos (MEDH) y

\footnotetext{
${ }^{65}$ Los indígenas en la Reforma Constitucional. Con presencia y protagonismo, ENDEPA-INCUPO, octubre de 1994, Repositorio ENDEPA.

${ }^{6}$ Op. cit., p. 6.

${ }^{67}$ Ibid., p. 12.

${ }^{68}$ Página/12, 12 de agosto de 1994, p. 7.

${ }^{69}$ ENDEPA, Documentos de ENDEPA, Memoria 2006. Formosa: Equipo Nacional de Pastoral Aborigen, 2007, p. 16.

${ }^{70}$ El Fondo para el Desarrollo de los Pueblos Indígenas de América Latina y El Caribe es un organismo multilateral de cooperación internacional abocado a "la promoción del autodesarrollo y el reconocimiento de los derechos de los Pueblos Indígenas". Fue creado en el seno de la II Cumbre Iberoamericana de Jefes de Estado y de Gobierno, realizada en 1992 en Madrid (http://www.fondoindigena.org/drupal/es/quees, fecha de consulta: 31 de agosto de 2017).

${ }^{71}$ Los indígenas en la Reforma Constitucional. Con presencia y protagonismo, ENDEPA-INCUPO, octubre de 1994, Repositorio ENDEPA.
} 
organizaciones indígenas como AIRA fueron autores de algunos de esos proyectos. Los vínculos que los agentes de pastoral mantenían con todas esas entidades facilitó la tarea de concordar los distintos proyectos bajo una misma propuesta. En efecto, el proyecto que ENDEPA presentó fue consensuado entre los abogados de su Asesoría Jurídica, los representantes de AIRA y otros abogados indígenas que también habían participado de la Declaración de Octubre. $^{72}$

El 6 de julio la comisión de Nuevos Derechos y Garantías emitió un despacho de mayoría dando cierre a la primera etapa de debates. El citado referente indígena Eulogio Frites (miembro de AIRA) calificó el despacho de Comisión como "un dictamen histórico"73. A continuación, el asunto pasó a manos de la Comisión de Redacción, en donde el artículo sufrió pocas, aunque cruciales modificaciones ${ }^{74}$. Finalmente, el 11 de agosto de 1994, fue aprobado por unanimidad. Buena parte de las formas definitivas del artículo replicaron literalmente exigencias plasmadas el año anterior en la Declaración de Octubre.

Como refirieron los diarios de la época, "las tribunas del recinto estaban colmadas por un centenar de representantes de comunidades indígenas de todo el país que habían fatigado los pasillos de la Universidad del Litoral desde el comienzo de la Convención". ${ }^{75} \mathrm{Al}$ decir de Gordillo y Hirsch, la sanción del artículo No 75 de la Constitución Nacional "galvanizó un notable nivel de militancia indígena". ${ }^{76}$

\section{Breve conclusión}

Con la sanción del artículo 75, inciso 17, la estructura jurídica argentina se inscribió dentro de lo que Van Cott (2000) denominó constitucionalismo "multicultural". Como se sabe, el caso local fue uno más entre una nutrida serie de reformas constitucionales producidas en distintos países latinoamericanos: Nicaragua (1986), Brasil (1988), Colombia (1991), Paraguay (1992), México (1992), Perú (1993), Bolivia (1994), Ecuador (1998) y Guatemala $(1998)^{77}$. Esta simultaneidad en los procesos de juridización de lo indígena muchas veces ha sido interpretada como el resultado, en parte, de las acciones de las denominadas

\footnotetext{
${ }^{72}$ Carrasco, op. cit.

${ }^{73}$ Página/12, 7 de julio de 1994, p. 10

${ }_{75}^{74}$ Ello es objeto pormenorizado de análisis en otras publicaciones Leone, op. cit., pp. 185 y ss.

${ }^{75}$ Página/12, 12 de agosto de 1994, p. 7.

76 Gordillo, Gastón y Hirsch, Silvia, "La presencia ausente: invisibilizaciones, políticas estatales y emergencias indígenas en la Argentina”, en: Gordillo, Gastón y Silvia Hirsch, (comps.), Movilizaciones indígenas e identidades en disputa en la Argentina, Buenos Aires: La Crujía, 2010, 29.

${ }^{77}$ Ciertamente, el grado de implementación de las políticas previstas en las reformas y de respeto de los derechos sancionados es asimétrico y variable. Cfr. Yrigoyen Fajardo, Raquel, "Hitos del reconocimiento del pluralismo jurídico y el derecho indígena en las políticas indigenistas y el constitucionalismo andino", en: Mikel Berrondo (coord..), Pueblos indígenas y derechos humanos, Bilbao: Universidad de Deusto, 2006, 537568; Clavero, Bartolomé, Derechos Indígenas y Constituciones Latinoamericanas. En: Berrondo, M. (coord.), Pueblos indígenas y derechos humanos, Bilbao, Universidad de Deusto, 2006, 313-338; entre otros.
} 
"advocacy networks" de tipo trasnacional ${ }^{78}$; lo cual tiene, sin duda, su parte de verdad. Sin embargo, en este artículo he querido presentar otra lectura posible sobre el mismo fenómeno. En tal sentido propuse una ilación históricamente fundamentada que permitiera interpretarlo -en sus causas y sus sentidos- como parte de un largo proceso iniciado, cuanto menos, hacia finales de la década de 1960. Como intenté demostrar, la naturaleza que tomó el proceso de sanción constitucional en 1994 consigue mejores explicaciones si se lo interpreta a la luz de la histórica conformación de un espacio político-pastoral interétnico territorialmente arraigado en las provincias de Formosa y Chaco y afín a las ideas de la teología de la liberación.

Luego, el análisis pormenorizado y en clave comparativa entre las tres instancias de juridización estudiadas (las "leyes aborígenes" formoseña y chaqueña y la reforma de la constitución nacional) puso en evidencia dinámicas semejantes de funcionamiento de la militancia por los derechos indígenas como son: a) la promoción de encuentros de referentes políticos indígenas; b) la participación en la elaboración de proyectos de ley; c) la producción de declaraciones conjuntas, pronunciamientos, etcétera; d) la generación de formas de representación ad hoc y la presencia en los debates legislativos; y e) la generación de vínculos, apoyaturas y solidaridades con distintos grupos, sectores y figuras políticas claves. El análisis en clave histórica, atendiendo a la conformación y desenvolvimiento de un específico espacio político-pastoral interétnico, permitió entender esas convergencias como el resultado, en parte, de la existencia de un mismo sustrato humano, político y militante operando en las distintas instancias.

En definitiva, esta manera de enfocar el problema de la juridización permite abrir el estudio de las dinámicas coyunturales en las que se produjeron las codificaciones jurídicas para reinsertarlo en un plano de análisis histórico más extenso. Permite también, entender los procesos concretos, las redes, las circulaciones - de personas, ideas, prácticas discursivas y no discursivas-, a través de las cuales distintos hitos en la juridización de los derechos indígenas pudieron cobrar forma.

\section{Bibliografía}

\section{Referencias bibliográficas}

Almirón, Victoria, "Alfabetización y textos de lectura en qom: Elena qataq Elí y Lede Na Qom (1964-1976)”, XXII Reunión de Comunicaciones Científicas y Tecnológicas de la Universidad Nacional del Nordeste. Corrientes, 14 y 15 de junio de 2016.

Barros Geraldo, Pedro; Fontainha, Fernando y Veronese, Alexandre, "Sociologia empírica do direito: Uma introdução", Revista Ética e Filosofia Política, № 12, vol. 2, Julho de 2010, 1-13.

\footnotetext{
${ }^{78}$ Van Cott, Donna Lee, The Friendly Liquidation of the Past. The Politics of Diversity in Latin America, Pittsburgh, University of Pittsburgh Press, 2000.
} 
Briones, Claudia, "Mestizaje y blanqueamiento como coordenadas de aboriginalidad y nación en Argentina", RUNA, XXIII, 2002, 61-88.

Briones, Claudia, "Formaciones de alteridad: contextos globales, procesos nacionales y provinciales", en: Briones, Claudia (ed.), Cartografías argentinas. Políticas indigenistas y formaciones provinciales de alteridad, Buenos Aires: Antropofagia, 2005, 11-43.

Brow, James, "Notes on community, hegemony, and the uses of the past", Anthropological Quarterly, nº 63, vol. 1, 1990, 1-6.

Carrasco, Morita, El movimiento indígena anterior a la reforma constitucional y su organización en el Programa de Participación de Pueblos Indígenas. Universidad de Buenos Aires, 2002. Recuperado de http://lanic.utexas.edu/project/etext/liilas/vrp/carrasco.pdf.

Comaroff, Jean y Comaroff, John L., "Naturalizando la nación: aliens, apocalipsis y el estado postcolonial", Revista de Antropología Social, (11), 2002, 89-133.

ENDEPA (2006), Documentos de ENDEPA, Memoria 2005, Formosa: Equipo Nacional de Pastoral Aborigen.

ENDEPA (2007), Documentos de ENDEPA, Memoria 2006. Formosa: Equipo Nacional de Pastoral Aborigen.

García-Ruíz, Jesús, "De la identidad aceptada a la identidad elegida: el papel de lo religioso en la politización de las identificaciones étnicas en Guatemala", Estudios Sociológicos X, $\mathrm{n}^{\circ} 30$, 1992, 713-733.

Gómez, Magdalena, "Derecho indígena y constitucionalidad", en: Krotz, Esteban (ed.), Antropología jurídica: perspectivas socioculturales en el estudio del derecho, Barcelona, Anthropos, 2002.

Gordillo, Gastón y Hirsch, Silvia, "La presencia ausente: invisibilizaciones, políticas estatales y emergencias indígenas en la Argentina", en: Gordillo, Gastón y Silvia Hirsch, (comps.), Movilizaciones indígenas e identidades en disputa en la Argentina, Buenos Aires: La Crujía, 2010, 15-38.

Guarino, Graciela, "Estrategias identitarias para la resistencia étnica en las organizaciones indígenas Qom del Chaco", Revista Mad, n 22, mayo de 2010, 56-72.

Harder Horst, Rene, "Breaking Down Religius Barriers. Indigenous People and Christian Churches in Paraguay", in: Edward L. Cleary and Timothy J. Steigenga, Resurgent Voices in Latina America: Indigenous Peoples, Political Mobiization and Religious Change, New Brunswick, New Jersey, London, Rutgers University Press, 2004, 65-92.

Iñigo Carrera, Nicolás, "La participación política de los indígenas chaqueños: algunos antecedentes, Misión Nueva Pompeya, 1952-1970”, en: Teurel, Ana y Omar Jeréz (eds.), Pasado y presente de un mundo postergado: estudios de antropología, historia y arqueología del Chaco Pedemonte Surandino, San Salvador de Jujuy: Universidad Nacional de Jujuy, 1998, 221-242.

Iturralde Guerrero, Diego, "Demandas indígenas y reforma legal: retos y paradojas", Alteridades, vol. 7, n 14, 1997, 81-98.

Leone, Miguel, "Prácticas de pastoral aborigen y juridización de derechos indígenas en Argentina. Un análisis de la región del Chaco (1965-1994)", Tesis doctoral inédita, Universidad Nacional de General Sarmiento-Instituto de Desarrollo Económico y Social, Los Polvorines, Buenos Aires, 1 de noviembre de 2016. 
Mombello, Laura, Evolución de la política indigenista en Argentina en la década de los noventa, Neuquén: Proyecto Self-Sustaining Community Development in Comparative Perspective, 2002.

Pacheco de Oliveira, João, Ensaios em Antropologia Histórica, Rio de Janeiro, UFRJ Editora, 1999.

Rancière, Jacques, El desacuerdo. Política y filosofía, Buenos Aires, Ediciones Nueva Visión, 1996.

Spadafora, Ana María; Gómez, Mariana y Matarrese, Marina, "Rumbos y laberintos de la política étnica: organizaciones unificadas y faccionalismos indígenas en la provincia de Formosa (pilagá y toba)", en: Gordillo, Gastón y Silvia Hirsch, (comps.), Movilizaciones indígenas e identidades en disputa en la Argentina, Buenos Aires: La Crujía, 2010, 237-258.

Taurozzi, Susana, Los pasionistas en Argentina y Uruguay: 100 años de historia, Buenos Aires, Pasionistas, 2006.

Touris, Claudia, "Entre Marianne y María. Los trayectos de las religiosas tercermundistas en la Argentina", en: Andújar, Andrea, D'Antonio, Débora, Gil Lozano, Fernanda, Grammático Karin y Rosa, María Laura (comps.), De minifaldas, militancias y revoluciones: Exploraciones sobre los `70, Buenos Aires: Luxemburg, 2009.

Van Cott, Donna Lee, The Friendly Liquidation of the Past. The Politics of Diversity in Latin America, Pittsburgh, University of Pittsburgh Press, 2000.

Zapata, Laura, "Pastoral aborigen y categorías de identificación de poblaciones indígenas en Formosa (1960-1984)", Uturunco Achachi. Revista de pueblos y culturas originarios, (2), diciembre 2013.

Žižek, Slavoj. "Multiculturalismo o la lógica cultural del capitalismo multinacional", en: Fredric Jameson y Slavoj Žižek, Estudios Culturales. Reflexiones sobre el Multiculturalismo, Buenos Aires, 2001, Paidós, 137-188.

\section{Publicaciones periódicas}

- Acción de Incupo, septiembre de 1990 / marzo de 1990 / julio de 1990

- Diario Norte, 14 de mayo,1987

- $\quad$ La Mañana, 24 de febrero de 1984 / 9 de abril de 1984

- $\quad$ Nuevo Diario, 26 de mayo de 1984

- Página/12, 11 de abril de 1994 / 7 de julio de 1994 / 26 de julio de 1994 / 12 de agosto de 1994 / Suplemento, 28 de agosto de 1994

- $\quad$ Porantim, año V, No 51, mayo de 1983 / año VII, Nº 68, octubre de 1984

\section{Documentos}

- 4to asamblea-encuentro Nacional. ENDEPA. Material de apoyo, 1990, CECAZO, f37, Formosa, Argentina.

- Breve Reseña del proyecto de Promoción de la comunidad toba-pilagá. Parroquia de Ibarreta, s/f [c. 1985], CECAZO, cajas, $n^{\circ}$ 203, Formosa, Argentina.

- Constitución Nacional Argentina (1994), art. 75, inc. 17

- Declaración de Octubre. Declaración de los representantes de los pueblos indígenas, Buenos Aires, 14 de octubre de 1993

- Diario de Sesiones HCD, Provincia de Chaco, 13 de mayo, 1987

- ENDEPA, informe 20 años de la Ley del Aborigen Chaqueño

- ENDEPA, Informe: "Para ir ampliando la información..." 
- Iluminación del equipo de Marins, c. 1984, p. 7, Archivo CECAZO, f66, Formosa, Argentina.

- HCD, Provincia de Formosa, exp. 335, 2 de agosto de 1984

- Los indígenas en la Reforma Constitucional. Con presencia y protagonismo, ENDEPAINCUPO, octubre de 1994

- Memoria de la creación de la Ley Integral del Aborigen, Taller de Formación y Diagnóstico Jurídico para hombres Wichí, Ingeniero Juárez. 19 al 21 de septiembre del 2005. Servicio Jurídico de Pueblos Indígenas del Centro Oeste de Formosa. Archivo privado de Francisco Nazar, Formosa, Argentina.

- Primer Encuentro de Pastoral Indigenista del Cono Sur de América Latina, 15 de febrero de 1980, Acervo do Instituto Socioambiental, São Paulo, Brasil.

- Reunión con asesores técnicos-ENDEPA. Tema Tierra, $1^{\circ}$ julio 1988, p. 1, CECAZO, c 35, Formosa, Argentina.

\section{Fuentes electrónicas}

- Fondo para el Desarrollo de los Pueblos Indígenas de América Latina y El Caribe, http://www.fondoindigena.org/drupal/es/quees, fecha de consulta: 31 de agosto de 2017

\section{Entrevistas}

- Entrevista a Ernesto Stechina realizada por el autor, 4 de julio de 2013, Formosa

- Entrevista a Mabel Quinteros realizada por el autor, 13 de abril de 2015, Buenos Aires 